Cemaliye Boylu Akyerli · Ŭgur Özbek

Müge Aydın-Sayitoğlu · Sema Sırma · Tayfun Özçelik

\title{
Analysis of MYH Tyr165Cys and Gly382Asp variants in childhood leukemias
}

Received: 4 March 2003 / Accepted: 4 July 2003 / Published online: 13 August 2003

(C) Springer-Verlag 2003

\section{Introduction}

DNA-repair gene mutations have been suspected as being a predisposing factor in the development of leukemia (Horwitz 1997). Our group identified one of the first examples of a DNA-repair gene mutation to be causally linked to childhood hematological malignancies and neurofibromatosis type I, which involves a homozygous germ-line mutation in the mismatch repair (MMR) gene MLH1 (Ricciardone et al. 1999; Wang et al. 1999). Subsequently, homozygous inactivation of MSH2, another MMR gene, was also found to be associated with early onset leukemia (Whiteside et al. 2002). It is well known that heterozygous germ-line mutations in the MMR pathway genes MLH1, MSH2, PMS2, PMS1, and MSH6 lead to hereditary nonpolyposis colorectal cancer (HNPCC) (Peltomaki 2001). Thus, tumorigenesis through an "MMR deficiency pathway" appears to be associated with two different disease phenotypes which are dependent on the status of the germ-line mutation: (a) HNPCC when the mutation is present on only one allele (heterozygous), and (b) hematological malignancies when the mutation(s) is present on both alleles (homozygous or compound heterozygous).

Base excision repair (BER) is another important DNA-repair pathway and plays a significant role in the repair of mutations generated by reactive oxygen species during aerobic metabolism. BER was not linked with any human genetic disorder until recently, when a

C. B. Akyerli · T. Özçelik $(\bowtie)$

Department of Molecular Biology and Genetics, Faculty of Science, Bilkent University, Bilkent, 06800 Ankara, Turkey E-mail: tozcelik@fen.bilkent.edu.tr

T. Özçelik

Ayhan Sahenk Foundation, 80670 Istanbul, Turkey

U. Özbek · M. Aydın-Sayitoğlu · S. Sırma

Department of Genetics, Institute for Experimental Medicine, Istanbul University, Çapa, 34280 Istanbul, Turkey
British family in which three siblings affected by multiple colorectal adenomas and carcinoma was shown to be compound heterozygous for $M Y H$ missense variants Tyr165Cys (Y165C) and Gly382Asp (G382D) (Al-Tassan et al. 2002). MYH is a homologue of E. coli mutY, and the mutations mentioned above affect residues that are conserved (Tyr82 and Gly253). Tyrosine 82 is predicted to function in mismatch specificity and is located in the pseudo-helix-hairpin-helix (Guan et al. 1998). Adenine glycosylase activity assays of the Tyr82Cys and Gly253Asp mutant proteins with 8-oxoG:A and G:A substrates show that their rate for adenine removal at $37^{\circ} \mathrm{C}$ is reduced by approximately $98 \%$ (Tyr82Cys) and 86\% (Gly253Asp) (Al-Tassan et al. 2002). Furthermore, bi-allelic germ-line mutations in $M Y H$ were identified in seven unrelated patients with colorectal adenomas (six with colorectal cancer) (Jones et al. 2002). Interestingly, the missense variations Tyr165Cys and Gly382Asp, which significantly reduce the adenine glycosylase activity of MYH protein, were each identified once in a normal control group of 100 British individuals with no history of colorectal adenoma or carcinoma (Al-Tassan et al. 2002). Since a connection between DNA-repair gene mutations and the path to hematological malignancy is now well established, and individuals who carry heterozygous $M Y H$ missense mutations Tyr165Cys and Gly382Asp have been documented in a control group (Al-Tassan et al. 2002), we investigated the association between these two MYH missense mutations and childhood leukemia risk.

\section{Results and discussion}

The study population included 185 cases of childhood leukemias subdivided into two groups: acute myeloid leukemia (AML; $n=45$ ) and acute lymphoblastic leukemia (ALL; $n=140$ ) diagnosed at Istanbul University between 1998 and 2002. Detailed clinical data are available for all patients. The French-American-British 
Cooperative Study Group criteria were used for histological subgroup classification (Cheson et al. 1990). Randomly selected Bilkent University students, with no history of hematological malignancies or any other type of cancer $(n=124)$, were genotyped in order for us to assess the status of the $M Y H$ mutations in apparently healthy Turkish individuals. Informed consent was obtained from all the students.

We screened for the MYH Tyr165Cys and Gly382Asp variants using genomic DNA as described (Al-Tassan et al. 2002). Neither mutation was present in any of the samples, except for that of one patient diagnosed with AML/M3. MYH Tyr165Cys mutation in the heterozygous state was present in the sample obtained at the time of initial diagnosis. Further sampling at remission, and the analysis of parental DNA, showed only the normal allele. Therefore, the mutation was considered to be specific for the leukemic blasts. It may be interesting to screen the whole $M Y H$ gene for mutations in hematological malignancies in the future, especially if increased transversions of $\mathrm{G}: \mathrm{C}$ to $\mathrm{T}: \mathrm{A}$ proved to be present in leukemic blasts. Based on these results, an association between childhood leukemias and the $M Y H$ missense variants Tyr165Cys and Gly382Asp was not observed. Also, these variants appear to be absent - if not at a very low frequency - in the Turkish population, contrary to the British population.

Acknowledgements This work was supported by SBAG-2513 from the Turkish Scientific and Technical Research Council (TÜBITTAK) and Bilkent University Research Fund.

\section{References}

Al-Tassan N, Chmiel NH, Maynard J, Fleming N, Livingston AL, Williams GT, Hodges AK, Davies DR, David SS, Sampson JR, Cheadle JP (2002) Inherited variants of $M Y H$ associated with somatic G:C $\rightarrow$ T:A mutations in colorectal tumors. Nat Genet $30: 227-232$
Cheson BD, Cassileth PA, Head DR, Schiffer CA, Bennett JM, Bloomfield CD, Brunning R, Gale RP, Grever MR, Keating MJ, Sawitsky A, Stass S, Weinstein H, Woods GW (1990) Report of the National Cancer Institute-sponsored workshop on definitions of diagnosis and response in acute myeloid leukemia. J Clin Oncol 8:813-819

Guan Y, Manuel RC, Arvai AS, Parikh SS, Mol CD, Miller JH, Lloyd S, Tainer JA (1998) MutY catalytic core, mutant and bound adenine structures define specificity for DNA repair enzyme superfamily. Nat Struct Biol 5:1058-1064

Horwitz M (1997) The genetics of familial leukemia. Leukemia 11:1347-1359

Jones S, Emmerson P, Maynard J, Best JM, Jordan S, Williams GT, Sampson JR, Cheadle JP (2002) Biallelic germline mutations in MYH predispose to multiple colorectal adenoma and somatic G:C $\rightarrow$ T:A mutations. Hum Mol Genet 11:2961-2967

Peltomaki P (2001) Deficient DNA mismatch repair: a common etiologic factor for colon cancer. Hum Mol Genet 10:735-740

Ricciardone MD, Özçelik $\mathrm{T}$, Cevher B, Özdağ H, Tuncer M, Gürgey A, Uzunalimoğlu Ö, Çetinkaya H, Tanyeli A, Erken E, Öztürk M (1999) Human MLH1 deficiency predisposes to hematological malignancy and neurofibromatosis type 1. Cancer Res 59:290-293

Whiteside D, McLeod R, Graham G, Steckley JL, Booth K, Somerville MJ, Andrew SE (2002) A homozygous germ-line mutation in the human $\mathrm{MSH} 2$ gene predisposes to hematological malignancy and multiple café-au-lait spots. Cancer Res 62:359-362

Wang Q, Lasset C, Desseigne F, Frappaz D, Bergeron C, Navarro C, Ruano E, Puisieux A (1999) Neurofibromatosis and early onset of cancers in $\mathrm{h} M L H 1$-deficient children. Cancer Res 59:294-297 